\title{
GREEN HERON AT DUNNET PARK
}

KEITH BARR, Regina, SK.

I took the photo of the green heron (Butorides virescens) at Dunnet Park near Avonlea, on Thursday May $8^{\text {th }} 2014$ and it was spotted on Wednesday May $7^{\text {th }}$. We spent about three hours there and took several photos and videos of it. Al [Smith] showed up to have another look at it when we were there. It was a nice warm sunny day.

Note: The green heron was seen from 7-11 May. This is the 20th record for the province and the first since 2007. It was seen in a tree bordered oxbow in Dunnet Park, which is pretty typical of it habitat farther south.

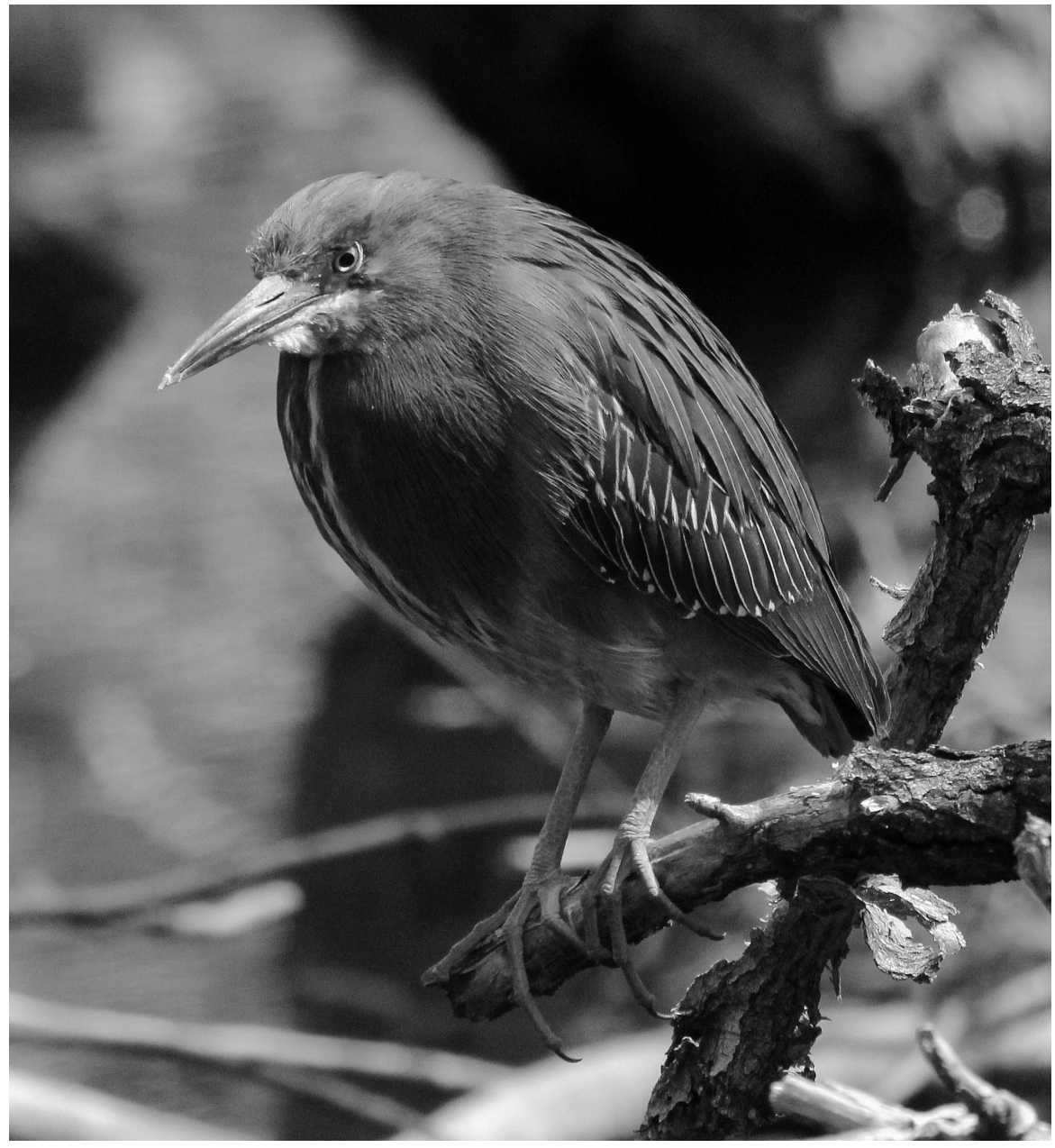

Green heron in a tree in Dunnet Regional Park, SK

- Keith Barr (for colour image, see outside back cover) 